\title{
Human Coronavirus-Associated Influenza-Like Illness in the Community Setting in Peru
}

\author{
Hugo Razuri,* Monika Malecki, Yeny Tinoco, Ernesto Ortiz, M. Claudia Guezala, Candice Romero, Abel Estela, \\ Patricia Breña, Maria-Luisa Morales, Erik J. Reaves, Jorge Gomez, Timothy M. Uyeki, Marc-Alain Widdowson, \\ Eduardo Azziz-Baumgartner, Daniel G. Bausch, Verena Schildgen, \\ Oliver Schildgen, and Joel M. Montgomery \\ United States Naval Medical Research Unit No. 6, Lima, Peru; Kliniken der Stadt Köln gGmbH, Klinikum der Privaten Universität Witten/ \\ Herdecke, Institut für Pathologie, Cologne, Germany; Clinica San Pablo, Lima, Peru; Influenza Division, U.S. Centers for Disease Control \\ and Prevention, Atlanta, Georgia; Department of Tropical Medicine, Tulane School of Public Health and Tropical Medicine, \\ New Orleans, Louisiana
}

\begin{abstract}
We present findings describing the epidemiology of non-severe acute respiratory syndrome human coronavirus-associated influenza-like illness from a population-based active follow-up study in four different regions of Peru. In 2010, the prevalence of infections by human coronaviruses 229E, OC43, NL63, or HKU1 was 6.4\% in participants with influenza-like illness who tested negative for influenza viruses. Ten of 11 human coronavirus infections were identified in the fall-winter season. Human coronaviruses are present in different regions of Peru and are relatively frequently associated with influenza-like illness in Peru.
\end{abstract}

\section{INTRODUCTION}

Infections of the respiratory tract continue to be a major cause of morbidity and mortality worldwide. Several studies in different settings have identified known respiratory viruses such as influenza, adenovirus, and respiratory syncytial virus as the main causes of respiratory infections. Until the last decade, a large proportion of respiratory illness remained undiagnosed because of a lack of widely used, accurate, and cost-effective diagnostics, especially in developing countries. Recent advances in molecular biology have led to the development and availability of standardized diagnostic tests and the discovery of new viruses. Novel respiratory viruses such as recently discovered human coronaviruses (HCoVs), human bocaviruses (HBoVs), and human metapneumoviruses are now recognized or suspected to be common causes of upper and lower respiratory tract disease. ${ }^{1}$ However, gaps remain in the knowledge of the distribution, epidemiology, and natural history of the diseases caused by these pathogens.

Coronaviruses are species of viruses belonging to the subfamily Coronavirinae within the Coronaviridae family. On the basis of the genome characteristics and serology, human coronaviruses are divided into three distinct groups. ${ }^{2}$ Coronaviruses recognized to infect humans belong to the genera Alphacoronavirus and Betacoronavirus. ${ }^{2,3}$ Two HCoVs (HCoV-229E and HCoV-OC43) were identified in the 1960s. ${ }^{4,5}$ For decades, these were the only HCoVs to be identified as possible agents of respiratory diseases and were primarily associated with upper respiratory tract illnesses. However, since the identification of severe acute respiratory syndrome-associated coronavirus in 2003, at least three new HCoVs have been identified; HCoV-NL63, a new Alphacoronavirus was identified in $2004 .^{6}$ In the same year, HCoV-HKU1 was discovered in Hong Kong. ${ }^{7}$ Most recently, the Middle East respiratory syndrome coronavirus, has earned worldwide attention. ${ }^{8,9}$

Human coronaviruses have been associated with a wide spectrum of respiratory diseases in different studies. In 2004,

* Address correspondence to Hugo Razuri, Research Institute of the McGill University Health Centre, 687 Pine Avenue Building V Rm V2.08, Quebec, Canada H3A1A1. E-mail: hugo.razuri@clinepi.mcgill.ca van Elden and others ${ }^{10}$ demonstrated the role of HCoVs as respiratory pathogens, reporting that HCoV-229 and/or $\mathrm{HCoV}-\mathrm{OC} 43$ were detected in $11 \%$ of patients with respiratory tract infections compared with $0.4 \%$ in control subjects. However, there is still debate about the pathogenic role of HCoVs in upper and lower respiratory diseases since later studies have found similar infection rates between sick and control subjects. ${ }^{11}$ Studies done in ambulatory and hospitalized patients report a variety of respiratory symptoms, with almost no difference between those caused by non-HCoVs and HCoVs. ${ }^{12}$

Human coronavirus infections have been reported globally in different groups of patients and in a wide variety of settings. ${ }^{13}$ Incidence of the four HCoVs varies according to the location and study population, with ranges from $0 \%$ to $8 \% .{ }^{14,15}$

Although the number of reports on HCoVs has increased in recent years, there is limited information on the incidence and epidemiology of these viruses as causes of ILI in the community setting, especially in low-and middle-income countries such as Peru. Furthermore, most studies have been performed through passive surveillance, precluding assessment of the burden of infection in the general population. We therefore tested respiratory samples collected from a prospective active surveillance cohort study on ILI in Peru for the presence of $\mathrm{HCoV}$.

\section{THE STUDY}

Respiratory samples were collected from persons with influenza-like illness (ILI) in an ongoing community-based prospective cohort study of approximately 7,000 participants in 1,500 households located in four geographically distinct locations in Peru: Lima (central coast/urban), Tumbes (tropical coast/rural), Cusco (highlands/semi-rural), and Puerto Maldonado (Amazon rainforest/urban), started in 2009. ${ }^{16}$ Households were randomly selected and participants were invited to participate in the study regardless of age. Household screening visits for ILI were made three times per week. ILI was defined as fever (temperature $\geq 38^{\circ} \mathrm{C}$ ) and either cough and/or sore throat in adults, adding runny nose in children. A questionnaire on potential risk factors and burden of disease was administered to all cases and a nasopharyngeal (NP) swab was collected for testing for influenza virus by real time reverse transcription polymerase chain reaction (real time 
RT-PCR). Cases were followed for 15 days after symptom onset to record full clinical evolution and economic expenses related to the disease episode.

NP samples were collected using Dacron swabs and placed immediately into universal transport media. Samples were transported to the laboratory in coolers at $4^{\circ} \mathrm{C}$ where they were kept in a $-70^{\circ} \mathrm{C}$ freezer, until transported to Naval Medical Research Unit No. 6 (NAMRU-6) for testing.

A total of 172 samples (from 96 males and 76 females) collected between January and December 2010 that tested negative for influenza viruses as well as 27 that were influenza positive (representing $8.2 \%$ of all samples collected in the study) were randomly selected for testing. All four sites were roughly evenly represented (44 from Lima, 51 from Tumbes, 37 from Cusco, and 40 from Puerto Maldonado), and the samples were roughly evenly distributed across the year (data not shown). Multiplex PCR was performed using the Luminex Respiratory Viral Panel assay (Austin, TX) for the following viruses: HCoV-HKU1, HCoV-NL63, HCoV-229E, $\mathrm{HCoV}-\mathrm{OC} 43$, influenza A and B, parainfluenza 1-4, adenovirus, entero-rhinovirus, and bocavirus.

Of the 172 samples that tested negative for influenza viruses, $11(6.4 \%)$ were positive for $\mathrm{HCoV}$, specifically HCoV-HKU1 (8), HCoV-NL63 (2), and HCoV-229E (1). HCoVs were identified in 7 males and 4 females and were mostly children (one 7-month-old and seven in the age group 1-5 years), although there were three adults (31, 32, and 59 years old). No coinfection with $\mathrm{HCoV}$ and other viruses were noted. Ten of the 11 persons with ILI in which HCoVs were identified had been sick between April and July, corresponding to autumn-winter in Peru (Figure 1). The only $\mathrm{HCoV}$ infection identified outside this period, in late spring, was HCoV-229. $\mathrm{HCoV}$ infections were identified from all four cohort sites: three from Lima, four from Cusco, and two each from Puerto Maldonado and Tumbes.

Persons with $\mathrm{HCoV}$ infections had a variety of upper respiratory infection symptoms, including cough, sore throat, headache, runny nose, and malaise. None of the individuals with $\mathrm{HCoV}$ infection had severe illness or required hospitalization. One 2-year-old child who tested positive for $\mathrm{HCoV}$ HKU1 experienced diarrhea in addition to ILI. There was no statistically significant difference in symptoms between

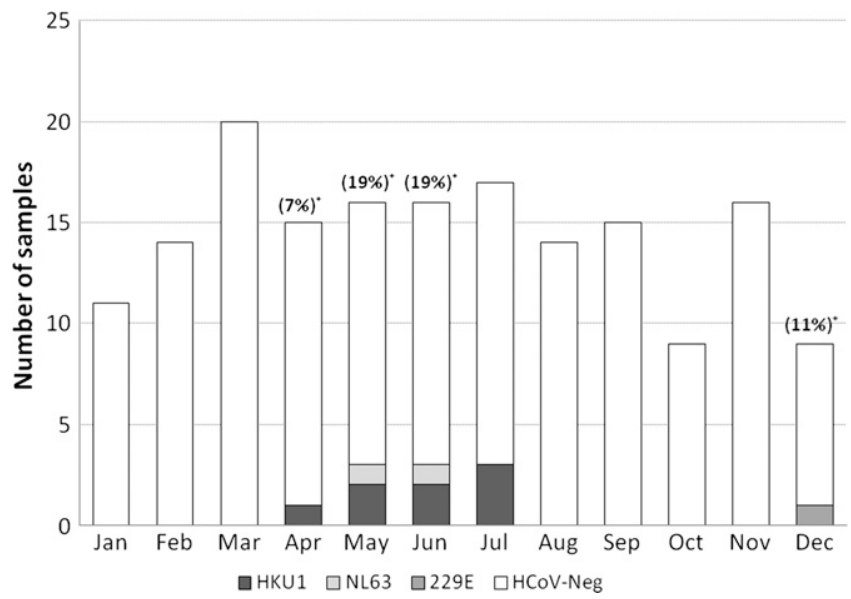

Figure 1. Temporal distribution of cases of influenza-like illness associated with human coronaviruses in four sites in Peru, 2010. * Human coronavirus monthly detection rate among influenza-negative samples. patients who had $\mathrm{HCoV}$ infection and those who did not (data not shown).

Ethics committee approval. The study was approved by the NAMRU-6 Institutional Review Board.

\section{CONCLUSIONS}

Our results suggest that $\mathrm{HCoVs}$, especially $\mathrm{HCoV}-\mathrm{HKU} 1$, are commonly associated with ILI in Peru, infecting persons across a broad age range. The prevalence of $\mathrm{HCoV}$ infection in our study was similar to that reported from other countries in Latin America. ${ }^{15}$ The fact that cases were seen in four geographically disparate surveillance sites suggests that $\mathrm{HCoVs}$ are widely distributed across the country and circulate in urban as well as rural areas and at varied altitudes and conditions of temperature and humidity. Although we report data from only 1 year of surveillance, there appeared to be a distinct seasonality, corresponding roughly to autumn and early winter in Peru (it should be noted that there is significant climatic variation between the four surveillance sites). Similar seasonal trends have been previously reported. ${ }^{12}$ This seasonal pattern could dilute the importance of these type of infections when examining only the yearly occurrence of this infections. For example, $13 \%$ of influenza-negative ILI would be associated with HCoVs during the fall-winter period in Peru (AprilSeptember). Moreover, if we restrict the analysis to the peak months, HCoVs would be associated with $19 \%$ of influenzanegative ILI infections in May and June 2010. Limitations to our study include the relatively small sample size, which precludes making associations with particular species of HCoVs, and the absence of an asymptomatic control group, precluding definitive conclusions on the causal nature of the $\mathrm{HCoV}$ found in each case of ILI. Nevertheless, in each case, HCoV was the only putative pathogen found. Further research and surveillance are needed to understand the detailed epidemiology and full scope of HCoVs as threats to public health in Peru and elsewhere.

Received April 8, 2015. Accepted for publication June 29, 2015.

Published online August 31, 2015.

Acknowledgments: We would like to thank Cecilia Gonzales for administrative support in preparing the manuscript.

Financial support: This project was partially supported by grants from the Else Kröner-Fresenius-Stiftung, Hesse, Germany, the U.S. Centers for Disease Control and Prevention, Atlanta, GA, and the Armed Forces Health Surveillance Center, Silver Spring, MD.

Copyright statement: Some of the authors of this manuscript are members of the U.S. Military or contractor employee of the U.S. Government. This work was prepared as part of their official duties. Title 17 U.S.C. $\$ 105$ provides that "Copyright protection under this title is not available for any work of the United States Government." Title 17 U.S.C. $\$ 101$ defines a U.S. Government work as a work prepared by a military service member or employee of the U.S. Government as part of that person's official duties.

Disclaimer: The views expressed in this article are those of the authors and do not necessarily reflect the official policy or position of the Department of the Navy, the Department of Defense, or the U.S. Government.

Authors' addresses: Hugo Razuri, Yeny Tinoco, Ernesto Ortiz, Claudia Guezala, Candice Romero, Abel Estela, Patricia Breña, Maria-Luisa Morales, Erik J. Reaves, and Joel M. Montgomery, Virology and Emerging Infections Department, U.S. Naval Medical Research Unit No.6, Callao, Peru, E-mails: hugorazuri@gmail.com, yeny.tinoco@ med.navy.mil, ernesto.ortiz@duke.edu, claudia.guezala@med.navy.mil, 
candice.romero@med.navy.mil, abelestela@gmail.com,patricia.brena.c@ gmail.com, malu.morales.fernandez@gmail.com, erikreaves@gmail.com, and jmontgomery@cdc.gov. Monika Malecki, Verena Schildgen, and Oliver Schildgen, Kliniken der Stadt Köln gGmbH, Klinikum der Privaten Universität Witten/Herdecke, Institut für Pathologie, Cologne, Germany, E-mails: maleckim@kliniken-koeln.de, schildgenv@klinikenkoeln.de, and schildgeno@kliniken-koeln.de. Jorge Gomez, Clinica San Pablo, Lima, Peru, E-mail: jlgomezb@gmail.com. Timothy M. Uyeki, Marc-Alain Widdowson, and Eduardo Azziz-Baumgartner, Influenza Division, U.S. Centers for Disease Control and Prevention, Atlanta, GA, E-mails: tmu0@cdc.gov, zux5@cdc.gov, and eha9@cdc.gov. Daniel G. Bausch, Virology and Emerging Infections Department, U.S. Naval Medical Research Unit No. 6, Callao, Peru, and Department of Tropical Medicine, Tulane School of Public Health and Tropical Medicine, New Orleans, LA, E-mail: dbausch@tulane.edu.

\section{REFERENCES}

1. Canducci F, Debiaggi M, Sampaolo M, Marinozzi MC, Berrè S, Terulla C, Gargantini G, Cambieri P, Romero E, Clementi M, 2008. Two-year prospective study of single infections and co-infections by respiratory syncytial virus and viruses identified recently in infants with acute respiratory disease. J Med Virol 80: 716-723.

2. Perlman S, Netland J, 2009. Coronaviruses post-SARS: update on replication and pathogenesis. Nat Rev Microbiol 7: 439-450.

3. Azhar EI, El-Kafrawy SA, Farraj SA, Hassan AM, Al-Saeed MS, Hashem AM, Madani TA, 2014. Evidence for camel-to-human transmission of MERS coronavirus. N Engl J Med 370: 2499-2505.

4. Hamre D, Procknow JJ, 1966. A new virus isolated from the human respiratory tract. Proc Soc Exp Biol Med 121: 190-193.

5. Tyrrell DA, Bynoe ML, 1965. Cultivation of a novel type of common-cold virus in organ cultures. BMJ 1: 1467-1470.

6. van der Hoek L, Pyrc K, Jebbink MF, Vermeulen-Oost W, Berkhout RJ, Wolthers KC, Wertheim-van Dillen PM, Kaandorp J, Spaargaren J, Berkhout B, 2004. Identification of a new human coronavirus. Nat Med 10: 368-373.

7. Woo PC, Lau SK, Chu CM, Chan KH, Tsoi HW, Huang Y, Wong BH, Poon RW, Cai JJ, Luk WK, Poon LL, Wong SS, Guan Y, Peiris JS, Yuen KY, 2005. Characterization and complete genome sequence of a novel coronavirus, coronavirus HKU1, from patients with pneumonia. J Virol 79: 884-895.
8. Assiri A, Al-Tawfiq JA, Al-Rabeeah AA, Al-Rabiah FA, Al-Hajjar S, Al-Barrak A, Flemban H, Al-Nassir WN, Balkhy HH, Al-Hakeem RF, Makhdoom HQ, Zumla AI, Memish ZA, 2013. Epidemiological, demographic, and clinical characteristics of 47 cases of Middle East respiratory syndrome coronavirus disease from Saudi Arabia: a descriptive study. Lancet Infect Dis 13: 752-761.

9. Fisman DN, Tuite AR, 2014. The epidemiology of MERS-CoV. Lancet Infect Dis 14: 6-7.

10. van Elden LJ, van Loon AM, van Alphen F, Hendriksen KA, Hoepelman AI, van Kraaij MG, Oosterheert JJ, Schipper P, Schuurman R, Nijhuis M, 2004. Frequent detection of human coronaviruses in clinical specimens from patients with respiratory tract infection by use of a novel real-time reversetranscriptase polymerase chain reaction. J Infect Dis 189: 652-657.

11. Prill MM, Iwane MK, Edwards KM, Williams JV, Weinberg GA, Staat MA, Willby MJ, Talbot HK, Hall CB, Szilagyi PG, Griffin MR, Curns AT, Erdman DD, New Vaccine Surveillance Network, 2012. Human coronavirus in young children hospitalized for acute respiratory illness and asymptomatic controls. Pediatr Infect Dis J 31: 235-240.

12. Gaunt ER, Hardie A, Claas EC, Simmonds P, Templeton KE, 2010. Epidemiology and clinical presentations of the four human coronaviruses 229E, HKU1, NL63, and OC43 detected over 3 years using a novel multiplex real-time PCR method. J Clin Microbiol 48: 2940-2947.

13. Perlman S, Netland J, 2009. Coronaviruses post-SARS: update on replication and pathogenesis. Nat Rev Microbiol 7: 439-450.

14. Woo PC, Lau SK, Yip CC, Huang Y, Yuen KY, 2009. More and more coronaviruses: human coronavirus HKU1. Viruses 1: $57-71$.

15. Cabeça TK, Passos AM, Granato C, Bellei N, 2013. Human coronavirus occurrence in different populations of Sao Paulo: a comprehensive nine-year study using a pancoronavirus RTPCR assay. Braz J Microbiol 44: 335-339.

16. Razuri H, Romero C, Tinoco Y, Guezala MC, Ortiz E, Silva M, Reaves E, Williams M, Laguna-Torres VA, Halsey ES, Gomez J, Azziz-Baumgartner E, Widdowson MA, Bresee J, Moen A, Uyeki TM, Bennett A, Montgomery JM, Bausch DG, 2012. Population-based active surveillance cohort studies for influenza: lessons from Peru. Bull World Health Organ 90: 318-320. 